\title{
评“2012 年诺贝尔化学奖”
}

\author{
杨帆，王江云* \\ 中国科学院生物物理研究所, 北京 100101 \\ * 联系人, E-mail: jwang@ibp.ac.cn
}

2012 年诺贝尔化学奖授予了美国的 Lefkowitz 教授和 Kobilka 教授, 奖励这两位生物化学家在 $\mathrm{G}$ 蛋白偶联受体 (GPCR)领域的重要贡献. $G$ 蛋白偶联受体又称作七次跨膜 受体, 是生物体内最大的膜蛋白受体超家族, 该受体家族 具有相似的结构, 其肽链由 $\mathrm{N}$ 末端, 7 次跨膜的的 $\alpha$ 螺旋, 3 个胞外环, 3 个胞内环和 $\mathrm{C}$ 末端组成(图 1) ${ }^{[1]}$, 因其能结合 $\mathrm{G}$ 蛋白而得名. GPCR 广泛参与人体内的各种生理过程，包括 生长、发育、精神及内分泌等多种生命活动，并且与心脏 病、糖尿病、肿瘤、精神疾病的发生有着密切的联系. 目 前市场上 $50 \%$ 以上的药物(如止痛剂、心脏平复药物、减肥 药物)的作用靶点都是 GPCR. 例如, 消化器官中存在的胆 囊收缩素受体, 能够控制我们的食欲和胆汁的分泌, 并且 可以调节胰岛素的分泌 ${ }^{[2]}$. 因此, 科学家合成出来了针对 这种 GPCR 的药物, 可以控制食欲以达到减肥的效果.

正因为 GPCR 的重要作用, 该领域一直受到科学家的 关注, 事实上这个领域不是第一次获得诺贝尔奖, 其中 Alfred Gilman 和 Martin Rodbell 因研究视觉系统中重要的 GPCR 视杆色素蛋白、揭示了光信号的转换机制, 而获得 了 1994 年的诺贝尔奖, Richard Axel 和 Linda B. Buck 发现 嗅觉受体是 GPCR, 并揭示了嗅觉的神经生理机制, 被授 予 2004 年的诺贝尔奖. Lefkowitz 利用同位素标记的方法证 明了 GPCR 的存在, 并且分离克隆了一系列 GPCR 基因, 其中他和他的博士后学生 Kobilka 将第一个 GPCR, 即 $\beta_{2}$ 肾上腺素受体的基因克隆出来. 虽然当时另一个 GPCR 视 杆色素的序列已经测出, 但当时并不知道视杆色素也是 GPCR, 直到将 Beta 2 肾上腺素受体基因克隆出来之后, 才 发现二者都是 7 次跨膜结构, 视杆色素也是 $\mathrm{GPCR}^{[3]}$. 肾上 腺素是一个重要的小分子物质, 在人体处于紧张或应激状 态时，肾上腺素会大量分泌，使心脏的收缩力增强，提高 应变能力. 在科学家发现肾上腺素受体是 GPCR 之前, 虽 然我们已经知道肾上腺素等很多小分子具有生物学效应, 具有药物价值, 但这些研究都是在黑暗中摸索, 我们并不 知道这些小分子是怎么发挥功能的. 直到 2007 年, GPCR 结构研究才有了重大的突破, 首先是 Kobilka 等人将单克 隆抗体 Mab5 结合到 $\beta_{2}$ 肾上腺素受体包内第 3 个环中, 得 到了分辨率为 $3.4 \AA$ 配体-受体晶体复合物，同年，Kobilka 等人又将 $\mathrm{T} 4$ 溶菌酶插人到 $\beta_{2}$ 肾上腺素受体的第 3 个胞内
环中, 得到了 $2.4 \AA$ 高分辨率的配体-受体复合物的晶体结 构. 随后利用这种方法, 更多的 GPCR 结构被解析出来. 通过这些结构信息我们可以发现，当激动剂作用于 $\beta_{2}$ 肾上 腺素受体时会引起受体的构象变化, 一个比较明显的现象 是 $\beta_{2}$ 肾上腺素受体的第 6 个跨膜的 $\alpha$ 螺旋(TM6)会发生较大 的位移. 研究还发现, 在不同的配体作用下, $\beta_{2}$ 肾上腺素受 体的构象会有不同的变化，从而介导不同的下游信号转导 途径 ${ }^{[4]}$. 这为药物设计提供了新的模型. 2011 年, Kobilka 等人又解析出了 $\beta_{2}$ 肾上腺素受体和 $\mathrm{G}$ 蛋白的复合物晶体结 构，该结构信息显示，当配体与 Beta 肾上腺素受体结合后, 会引起受体的构象变化, 使第 6 个跨膜的 $\alpha$ 螺旋(TM6)向胞 外产生 $14 \AA$ 的位移，同时还发现 Gs 的 $\alpha$ 亚基也会有较大的 移动, 从而使 GTP 酶结合到受体上, 实现 GDP 与 GTP 的 转换, 进而启动下游的信号转导途径 ${ }^{[5]}$. 这些结构上的突 破为药物研发提供了极大的帮助, 使我们能够开发出更有 靶向性的小分子药物 ${ }^{[5]}$.

我们也从事 GPCR 领域的相关工作, 并提出了嗅觉受 体是金属离子依赖的理论(图 1). 化学家都知道, 多数和铜 离子强烈作用的挥发性小分子, 如硫化氢或氨都有强烈的 气味, 因此我们提出嗅觉受体的活性位点可能含有铜离子. 我们找到了结合过渡金属离子的位点, 并合成了这一段多 肽, 发现它可以结合 $\mathrm{Cu}^{\mathrm{II}}$, 并且在结合后成为 $\alpha$ 螺旋构象. 根据这一实验结果, 结合隐藏马科夫模型, 我们提出了嗅 觉受体信号转导的“羽毛球”模型, 即嗅觉受体通过第 4 个 跨膜的 $\alpha$ 螺旋的活塞式运动而介导信号转导的机制 ${ }^{[7]}$.

这次诺贝尔奖化学奖不仅仅是 Lefkowitz 教授和 Kobilka 教授的荣誉, 也是对有机化学家和药物化学家的 褒奖. 因为他们的创造性工作, 合成篮选出非常有效的小 分子药物, 使得基础研究走出实验室, 真正造福人类. 但这个领域还有很多重要的问题。首先是我们现在有这么 多结构信息, 基于对结构的了解, 我们怎样设计出更加有 效的、副作用更小的药物? 另一个问题是：小分子结合怎 样诱导 GPCR 的动态变化, 使膜外的信号能够被传递到膜 内? 这将需要发展一系列的苂光及核磁探针, 以检测 GPCR 不同时间及空间尺度的构象变化. 所有这些问题的 解决需要结构生物学家、有机化学家、物理化学家进行通 力合作 

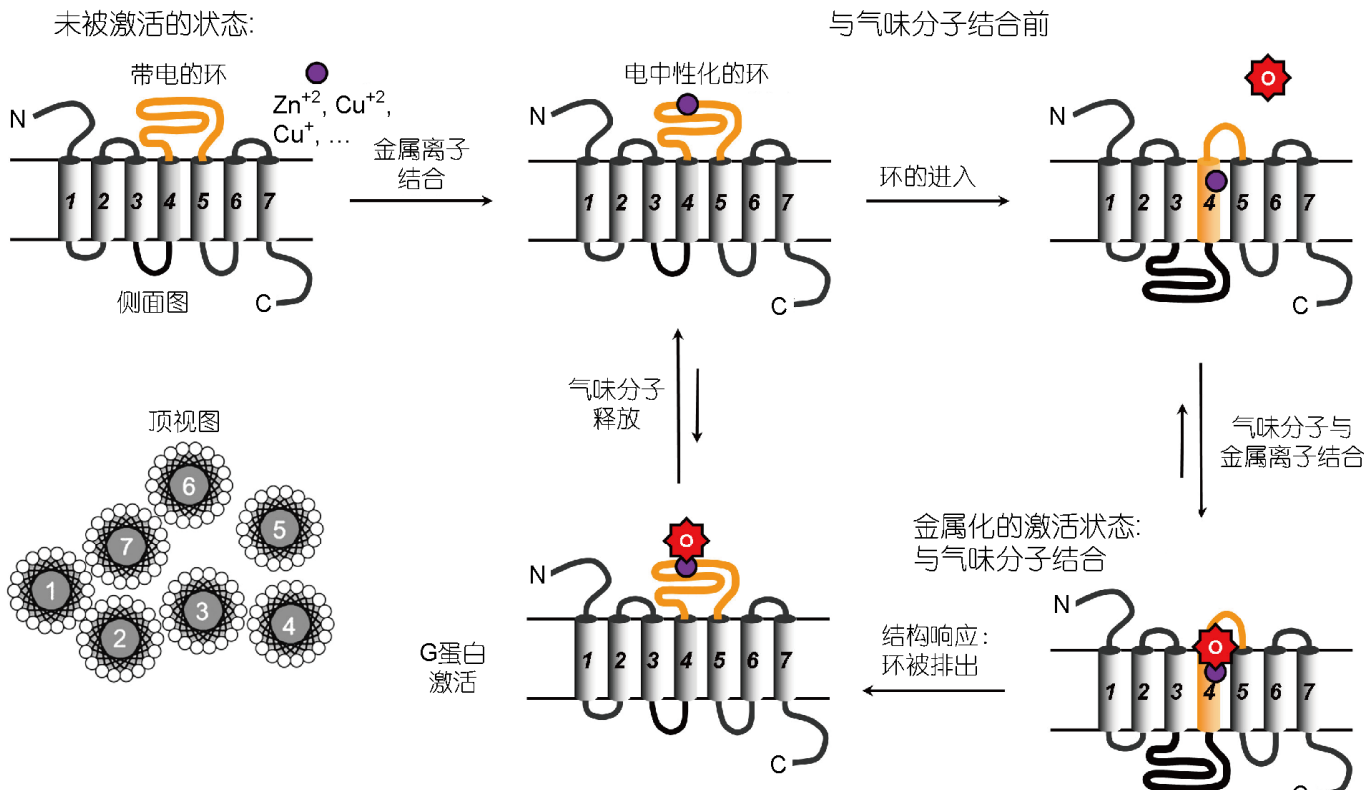

金属化的激活状态:

气味分子结合

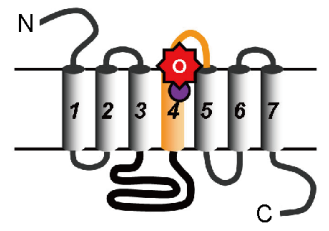

图 1 嗅觉受体(GPCR 的一种)感知气味分子的“羽毛球”模型

\section{推荐阅读文献}

1 Trzaskowski B, Latek D, Yuan S, et al. G-protein-coupled receptor dynamics: Dimerization and activation models compared with experiment. Biochem Soc Trans, 2012, 40: 394-399

2 Lavine J A, Raess P W, Stapleton D S, et al. Cholecystokinin is up-regulated in obese mouse islets and expands beta-cell mass by increasing beta-cell survival. Endocrinology, 2010, 151: 3577-3588

3 Palczewski K, Kumasaka T, Hori T, et al. Crystal Structure of Rhodopsin: A G protein coupled receptor. Science, 2000, 289: 739-745

4 Cherezov V, Rosenbaum D M, Hanson M A, et al. High-resolution crystal structure of an engineered human $\beta 2$-adrenergic G proteincoupled receptor. Science, 2007, 318: 1258-1265

5 Rasmussen S G F, Devree B T, Zou Y Z, et al. Crystal structure of the $\beta 2$ adrenergic receptor-Gs protein complex. Nature, 2011, 477: $549-555$

6 Audet M, Bouvier M. Restructuring G-protein-coupled receptor activation. Cell, 2012, 151: 14-23

7 Wang J Y, Luthey-Schulten Z A, Suslick K S. Is the olfactory receptor a metalloprotein? Proc Natl Acad Sci USA, 2003, 100: 3035-3039 